\title{
Neostigmine requirements for reversal of neuromus- cular blockade following an infusion of mivacurium
}

Martin R. Lessard MD FRCPC, Claude A. Trépanier MD FRCPC, Jean-François Rouillard MD FRCPC

Purpose: To study the efficacy of neostigmine compared with placebo for the antagonism of neuromuscular blockade at the end of a mivacurium infusion, and to determine its optimal dose.

Methods: One hundred adult patients undergoing an elective surgical procedure received a standardized anaesthetic with 20-30 $\mu \mathrm{g}^{\mathrm{kg}} \mathrm{g}^{-}$affentanil, a propofol infusion and nitrous oxide. Muscle relaxation was maintained at $90-95 \%$ TI depression with $0.2 \mathrm{mg} \cdot \mathrm{kg}^{\prime}$ mivacurium followed by an infusion. Neuromuscular blockade was measured with an integrated evoked electromyogram in response to train-of-four (TOF) stimuli at the ulnar neve every $20 \mathrm{sec}$. Patients were randomized into four groups. At the end of surgery, the mivacurium infusion was stopped and patients received, immediately, in a double-blind manner, neostigmine $\left(10,20\right.$, or $\left.40 \mu \mathrm{g} \cdot \mathrm{kg}^{\prime}\right)$ or placebo according to a random number table. The $\mathrm{TI}$ and TOF ratio were reconded until adequate recovery of neuromuscular function (TOF ratio $>0.70$ ). During the reversal period, non-invasive blood pressure and heart rate were recorded every minute. The incidence of postoperative nausea and vomiting (PONV) was recorded in the recovery room.

Results: Data from 94 patients who completed the protocol were analysed. Compared with placebo, neostigmine $10 \mu \mathrm{gkg}^{-1}$ did not reduce the time to TOF $>0.70(17.0 \pm 5.1 \mathrm{vs} 14.6 \pm 4.2 \mathrm{~min}$ respectively). However the time was decreased with neostigmine $20 \mu \mathrm{g} \cdot \mathrm{kg}^{-1}$ and $40 \mu \mathrm{g} \cdot \mathrm{kg}^{-1}(P<0.001)$. but with no difference between these last two groups ( $11.4 \pm 3.0$ and $11.4 \pm 3.5 \mathrm{~min}$ respectively). Changes in systolic blood pressure and heart rate were not different between the four groups. Very few PONV events were observed in all groups (global incidence 7.4\%).

Conclusion: Recovery of neuromuscular blockade following a mivacunium infusion is accelerated by neostigmine. A dose of neostigmine $20 \mu \mathrm{g} \cdot \mathrm{kg}^{\prime}$ appears optimal with no further reduction in recovery time obtained from a larger dose.

Objectif : Comparer l'efficacité de la néostigmine à celle d'un placebo administrée pour la décurarisation à la fin d'une perfusion de mivacunium et en déterminer la dose optimale.

Méthodes : Cent adultes soumis à une chinurgie élective ont reçu une anesthésie standardisée comprenant alfentanil 20-30 $\mu \mathrm{g}^{\mathrm{kg}} \mathrm{kg}^{-1}$, une perfusion de propofol et du protoxyde d'azote. La curansation était maintenue à 90-95\% de dépression de $\mathrm{Tl}$ avec une dose de mivacurium $0,2 \mathrm{mg} \mathrm{kg}^{-}$suivi d'une pertusion. L'électromyographie évoquée intégrée servait à évaluer la curarisation au nerf cubital avec la réponse à la stimulation au train-de-quatre (TOF) à toutes les 20 secondes. Les patients étaient répartis en quatre groupes. À la fin de la chirurgie, une fois la perfusion de mivacurium cessée, les patients, immédiatement et en double aveugle, recevaient la néostigmine $\left(10,20 \mathrm{ou} 40 \mu \mathrm{g} \cdot \mathrm{kg}^{-1}\right)$ ou le placebo conformément à une table de nombres au hasard. On enregistrait TI et le rapport TOF jusqu'à la reprise de la fonction neuromusculaire (rapport TOF $>0.70$ ). Pendant la période de décurarisation, on enregistrait à la minute la pression artérielle non invasive et la fréquence cardiaque. Lincidence des nausées et des vomissements postopératoires (NVPO) était notée en salle de réveil,

Résultats : Les données des 94 patients qui ont complété l'étude ont été analysées. Comparativement au placebo, la néostigmine $10 \mu \mathrm{g} \cdot \mathrm{kg}^{-1}$ n'a pas diminué le délai jusqu'au TOF $>0,70$ (respectivement 17,0 $\pm 5,1$ vs 14,6 44,2 $\mathrm{min})$. Cependant, cet intervalle diminuait avec la néostigmine $20 \mu \mathrm{g}^{\mathrm{kg}}$ et $40 \mu \mathrm{g}^{-1} \mathrm{~kg}^{-1}(P<0,001)$ mais sans qu'il n'y ait de différence entre ces deux demiers groupes (respectivement $11,4 \pm 3,0$ et $11,4 \pm 3.5$ ). Les changements de pression systolique et de fréquence cardiaque ne différaient pas entre les quartres groupes. Très peu de NVPO ont été observés dans tous les groupes (incidence globale 7,4\%).

Conclusion : Après le mivacurium en perfusion, la décurarisation est accélérée par la néostigmine. La dose de 20 $\mu \mathrm{g} \cdot \mathrm{kg}^{\prime}$ semble optimale.

From the Département d'anesthésic-réanimation, Hôpital de l'Enfant-Jésus, 1401, 18 iene Rue, Québec, P. Québec, Canada GIJ 1Z4 Supported by a grant from Burroughs-Wellcome Canada Inc.

Address correspondence to: Martin Lessard MD; Phone: 418-649-5807; Fax: 418-649-5918; E-mail: martin.lessard@anr.ulaval.ca

Presented in part at the annual meeting of Société Française d'Anesthésie-Réanimation, Paris, France, September 1995.

Accepted for publication, le 3 mai 1997. 
M IVACURIUM is a non depolarizing muscle relaxant with a short elimination half life and a rapid spontaneous recovery. This short duration of action is the result of rapid breakdown by plasma cholinesterase. ${ }^{1-3}$ Because of this rapid breakdown and spontaneous recovery, it has been questioned whether the reversal of mivacurium by anticholinesterase agents at the end of surgery is necessary. ${ }^{3-5}$ Neostigmine is an anticholinesterase whose onset of action is between 7 and 11 min. ${ }^{6-7}$ Since the mean time of spontaneous recovery of mivacurium from a $95 \%$ block to $5 \%$ has been reported to be about $17 \mathrm{~min},{ }^{2}$ one might wonder if the few minutes that might be gained with the use of reversal agents are clinically relevant. Besides, avoiding reversal drugs might reduce the incidence of undesirable side effects such as cardiac arrythmia, increased bowel motility and postoperative nausea and vomiting. ${ }^{6,8-11}$

Moreover, it has also been suggested that neostigmine, beside its inhibiting effect on acetylcholinesterase, might also have a similar effect on plasma cholinesterases thus limiting the breakdown of mivacurium and potentially impeding recovery of neuromuscular function. ${ }^{12}$ It has been reported that neostigmine is less effective in antagonizing the effect of mivacurium than that of vecuronium, and that neostigmine increases the plasma concentration of mivacurium. ${ }^{13}$ This might potentially decrease the efficacy of neostigmine in antagonizing mivacurium. This study was undertaken to determine whether neostigmine increases the speed of recovery from a constant neuromuscular blockade induced by an infusion of mivacurium and, if so, to determine its optimal dose.

\section{Methods}

The protocol was approved by the Hospital Ethics Committee and written informed consent was obtained from each patient before inclusion in the study. One hundred patients aged between 18 and $60 \mathrm{yr}$, ASA physical status I or II, scheduled for an elective surgical procedure of 30-120 min duration with general anaesthesia were included in the study. Exclusion criteria were: any neurological, neuromuscular, renal or hepatic disease, intake of any medication known to interfere with neuromuscular function, history of allergy to one of the study medications, extremes of body weight (body mass index $<20 \mathrm{~kg} \cdot \mathrm{m}^{-2}$, or $>30 \mathrm{~kg} \cdot \mathrm{m}^{-2}$ ), and pregnancy.

\section{Anaesthetic protocol}

Upon arrival in the operating room, an intravenous infusion of Ringer's lactate solution was started using a large bore antecubital vein. Monitoring included two-lead ECG, non-invasive blood pressure, nasopharyngeal tem- perature, oxygen saturation, and $\mathrm{P}_{\mathrm{ET}} \mathrm{CO}_{2}$. Neuromuscular function was monitored with the Puritan Bennett Datex $^{\text {TM }} 221$ NMT Relaxograph monitor. Anaesthesia was induced with alfentanil $20-30 \mu \mathrm{g} \cdot \mathrm{kg}^{-1}$ and propofol 2-3 $\mathrm{mg} \cdot \mathrm{kg}^{-1}$. The lungs were manually ventilated by mask with $\mathrm{O}_{2} 100 \%$ while the Relaxograph monitor was calibrated. After a stable baseline response was obtained, a bolus of $0.2 \mathrm{mg} \cdot \mathrm{kg}^{-1}$ mivacurium was administered with a Bard InfusOR ${ }^{\mathrm{TM}}$ pump. The trachea was intubated when maximal relaxation was reached. When $\mathrm{Tl}$ had recovered to $5 \%$, an infusion of mivacurium was started at $6 \mu \mathrm{g} \cdot \mathrm{kg}^{-1} \cdot \mathrm{min}^{-1}$ and adjusted at five minute intervals to maintain 90 to $95 \%$ depression of the first twitch of the train-of-four (TOF) for the duration of the surgery. Controlled ventilation was adjusted to keep the $\mathrm{P}_{\mathrm{ET}} \mathrm{CO}_{2}$ between 35 and $40 \mathrm{mmHg}$. Anaesthesia was maintained with incremental doses of alfentanil, an infusion of propofol and a mixture of $\mathrm{N}_{2} \mathrm{O} / \mathrm{O}_{2}(70 \% / 30 \%)$. No other inhalational agent was used at any time during anaesthesia.

\section{Protocol for reversal of neuromuscular blockade}

Patients were randomized into four groups and received $0.2 \mathrm{ml} \cdot \mathrm{kg}^{-1}$ from a coded syringe. According to the patient study group, the contents of the coded syringe were:

Group 1 (control): Normal Saline (NS) $20 \mathrm{ml}$

Group 2 (neostigmine $10 \mu g \cdot \mathrm{kg}^{-1}$ and glycopyrrolate $\left.2.5 \mu \mathrm{g} \cdot \mathrm{kg}^{-1}\right)$ : Neostigmine l $\mathrm{mg}(2 \mathrm{ml})+$ Glycopyrrolate $0.25 \mathrm{mg}$ $(1.25 \mathrm{ml})+\mathrm{NS} 16.75 \mathrm{ml}$

Group 3 (neostigmine $20 \mu \mathrm{g} \cdot \mathrm{kg}^{-1}$ and glycopyrrolate $5 \mu \mathrm{g} \cdot \mathrm{kg}^{-1}$ ): Neostigmine $2 \mathrm{mg}$ $(4 \mathrm{ml})+$ Glycopyrrolate $0.5 \mathrm{mg}(2.5 \mathrm{ml})+$ NS $13.5 \mathrm{ml}$

Group 4 (neostigmine $40 \mu \mathrm{g} \cdot \mathrm{kg}^{-1}$ and glycopyrrolate $10 \mu \mathrm{g} \cdot \mathrm{kg}^{-1}$ ): Neostigmine $4 \mathrm{mg}(8 \mathrm{ml})+$ Glycopyrrolate $1.0 \mathrm{mg}(5 \mathrm{ml})$ $+\mathrm{NS} 7 \mathrm{ml}$

The syringes were prepared by the pharmacy department and the investigators were unaware of their contents. At the end of surgery, the infusion of mivacurium was stopped and the study medication was administered. A stable level of anaesthesia was maintained until adequate recovery from neuromuscular blockade (TOF ratio $>0.70$ ). Nitrous oxide and propofol were then discontinued and the trachea was extubated when the patient was awake and able to sustain a five second head lift. If neuromuscular. function had not adequately recovered $20 \mathrm{~min}$ after the administration of the study medication, neostigmine $40 \mu \mathrm{g} \cdot \mathrm{kg}^{-1}$ and glycopyrrolate $10 \mu \mathrm{g} \cdot \mathrm{kg}^{-1}$ were given as a rescue reversal medication. Following tracheal extubation, patients were 
transferred to the recovery room for standard care and monitoring for at least $60 \mathrm{~min}$. The period beginning with discontinuation of the mivacurium infusion and ending with adequate recovery of neuromuscular function was named the Reversal Period.

\section{Measurements}

Neuromuscular blockade was measured using an integrated evoked electromyogram (EMG). Response to supramaximal TOF stimuli, with impulses of $0.1 \mathrm{msec}$ duration at a frequency of $2 \mathrm{~Hz}$, was measured every 20 sec with a Puritan Bennett Datex 221 NMT Relaxograph monitor. The stimuli were applied at the ulnar nerve above the wrist with surface electrodes and the evoked EMG response of the adductor pollicis was recorded. The monitor was calibrated after induction of anaesthesia and prior to the administration of mivacurium. Values of Tl (\% control) and of TOF ratio were recorded every $20 \mathrm{sec}$ during the induction phase, every five minutes during the surgical procedure, and again every $20 \mathrm{sec}$ during the reversal period. Adequate recovery of neuromuscular function was defined as a TOF ratio $>0.70$. Since $\mathrm{Tl}$ rarely recovered to $100 \%$ of control even when TOF ratio was $>0.70$, the $\mathrm{Tl}$ values recorded during the reversal period were recalculated as a percentage of the final $\mathrm{Tl}$ height when TOF ratio had recovered $>0.70 .{ }^{14}$ This value was named $\mathrm{Tl}$ corrected (Tlc), and was used in all subsequent analysis. During the reversal period, non-invasive blood pressure and heart rate were measured and recorded every minute from the cardiovascular monitor $\left(\right.$ Spacelabs $^{\mathrm{TM}}$, Redmond, Washington). In the recovery room, frequency of postoperative nausea and vomiting (PONV) was recorded during the first $60 \mathrm{~min}$ after surgery by the attending nurse who was unaware of the patient study group.

\section{Statistical analysis}

Data are reported as mean $\pm \mathrm{SD}$ or percentages. Continuous parametric variables were analysed using one-way analysis of variance (ANOVA) or repeated measures ANOVA, and the Tukey-Kramer multiple comparisons test when appropriate. Non parametric variables were compared with the Chi-square test with Bonferroni correction for multiple comparisons. A probability level less than 0.05 was considered significant.

\section{Results}

One hundred patients were included in the study. Six patients were subsequently excluded for the following reasons: technical failure of the NMT monitor, one patient; shortened procedure preventing the establishment of the mivacurium infusion, one patient; prolonged neuromuscular blockade ( $>45 \mathrm{~min}$ ) following the bolus dose of mivacurium, one patient; excessive recovery of $\mathrm{Tl}$ at the end of mivacurium infusion ( $\mathrm{Tl}>15 \%$ ), three patients. Thus, 94 patients were included in the final analysis.

Patient characteristics and clinical data are summarized in Table I. There was no difference among groups for age, weight, sex, type of surgical procedure, duration of anaesthesia, total dose of alfentanil and propofol received. Data on mivacurium neuromuscular blockade and reversal are presented in Table II. The dose and the duration of mivacurium infusion were not different among the four groups. Recovery of the first twitch at the end of infusion (Tlc end of infusion) was not different either.

Recovery of Tlc and of Tlc $25-75 \%$ was reduced in the three neostigmine groups compared with placebo (Table II, Figure 1). Recovery of TOF ratio was shortened both in the 20 and $40 \mu \mathrm{g} \cdot \mathrm{kg}^{-1}$ neostigmine groups

TABLE I Demographic and clinical data

\begin{tabular}{|c|c|c|c|c|}
\hline & Control & $\begin{array}{l}\text { Neostigmine } \\
10 \mu g \cdot \mathrm{kg}^{-1}\end{array}$ & $\begin{array}{l}\text { Neostigmine } \\
20 \mu g \cdot \mathrm{kg}^{-1}\end{array}$ & $\begin{array}{l}\text { Neostigmine } \\
40 \mu g \cdot \mathrm{kg}^{-1}\end{array}$ \\
\hline Number of patients & 24 & 25 & 22 & 23 \\
\hline Age $(y r)$ & $41.6 \pm 12$ & $33.8 \pm 12$ & $40.1 \pm 12$ & $36.6 \pm 9$ \\
\hline Weight $(\mathrm{kg})$ & $74.2 \pm 13$ & $74.3 \pm 13$ & $78.0 \pm 13$ & $68.3 \pm 9$ \\
\hline $\operatorname{Sex} m / f(n)$ & $15 / 9$ & $18 / 7$ & $16 / 6$ & $14 / 9$ \\
\hline ASA physical status (I/II) & $24 / 0$ & $25 / 0$ & $20 / 2$ & $20 / 3$ \\
\hline \multicolumn{5}{|l|}{ Type of surgery (\%) } \\
\hline - General & 17 & 4 & 18 & 17 \\
\hline - Orthopaedic & 62 & 88 & 64 & 65 \\
\hline - Gynaecological & 21 & 8 & 18 & 17 \\
\hline Duration of anaesthesia (min) & $76 \pm 20$ & $75 \pm 22$ & $88 \pm 38$ & $75 \pm 19$ \\
\hline Dose of alfentanil $(\mathrm{mg})$ & $2.1 \pm 0.8$ & $2.4 \pm 1.3$ & $2.5 \pm 1.1$ & $2.3 \pm 0.9$ \\
\hline Dose of propofol (mg) & $764 \pm 273$ & $838 \pm 344$ & $941 \pm 383$ & $777 \pm 224$ \\
\hline
\end{tabular}

Data are mean $\pm S D$, or ratio (\%);

$P=$ NS between the four groups for all variables. 
TABLE II Charactcristics of mivacurium neuromuscular blockade and recovery

\begin{tabular}{|c|c|c|c|c|}
\hline & Control & $\begin{array}{l}\text { Neostigmine } \\
10 \mathrm{\mu g} \cdot \mathrm{kg}^{-1}\end{array}$ & $\begin{array}{l}\text { Neostigmine } \\
20 \mu g \cdot \mathrm{kg}^{-1}\end{array}$ & $\begin{array}{l}\text { Neostigmine } \\
40 \mathrm{Hg} \cdot \mathrm{kg}^{-1}\end{array}$ \\
\hline Number of patients & 24 & 25 & 22 & 23 \\
\hline \multicolumn{5}{|l|}{ Dose of mivacurium (mg) } \\
\hline - Infusion & $24.9 \pm 16$ & $28.5 \pm 24$ & $40.4 \pm 33$ & $25.3 \pm 17$ \\
\hline - Total dose (initial bolus and infusion) & $40.0 \pm 18$ & $43.7 \pm 25$ & $56.7 \pm 34$ & $39.9 \pm 19$ \\
\hline Duration of infusion ( $\mathrm{min}$ ) & $49.6 \pm 18$ & $48.8 \pm 20$ & $65.4 \pm 36$ & $53.6 \pm 19$ \\
\hline Tl maximal recovery (\% Tl control) & $88.6 \pm 15$ & $81.5 \pm 14$ & $86.3 \pm 17$ & $79.3 \pm 16$ \\
\hline Tlc end of infusion (\%) & $5.1 \pm 3$ & $7.6 \pm 5$ & $6.7 \pm 3$ & $6.5 \pm 4$ \\
\hline Time to Tlc $>95 \%(\mathrm{~min})$ & $16.0 \pm 4.5$ & $12.4 \pm 3.9^{\dagger}$ & $10.3 \pm 2.9$ & $10.3 \pm 3.6^{t}$ \\
\hline Recovery index $(25-75 \%)(\mathrm{min})$ & $5.6 \pm 1.8$ & $4.3 \pm 1.6^{*}$ & $3.6 \pm 1.1^{\ddagger}$ & $3.5 \pm 1.5 \ddagger$ \\
\hline Time to TOF ratio $>70 \%(\mathrm{~min})$ & $17.0 \pm 5.1$ & $14.6 \pm 4.2$ & $11.4 \pm 3.0 \pm \$$ & $11.4 \pm 3.5^{\ddagger \S}$ \\
\hline \multicolumn{5}{|l|}{ Mean difference in time to TOF ratio $>70 \%$, each } \\
\hline neostigmine group minus Control group $(95 \% \mathrm{CI})(\mathrm{min})$ & - & $2.4(-0.6-5.5)$ & $5.6(2.5-8.8)$ & $5.6(2.5-8.7)$ \\
\hline Heart rate (at reversal drug injection) & $61.8 \pm 9.3$ & $57.1 \pm 9.3$ & $64.0 \pm 7.7$ & $67.0 \pm 10.5$ \\
\hline Systolic blood pressure (at reversal drug injection) & $105.5 \pm 12.5$ & $105.9 \pm 17.3$ & $114.9 \pm 16.6$ & $111.2 \pm 16.6$ \\
\hline
\end{tabular}

Data are mean $\pm \mathrm{SD}$, or ratio $(\%)$;

$* P<0.05$ vs Control

$1 P<0.01$ vs Control

$\pm P<0.001$ ps Control

$\$ P<0.05$ vs neostigmine $10 \mu \mathrm{g} \cdot \mathrm{kg}^{-1}$ group

$P=$ NS for all other comparisons

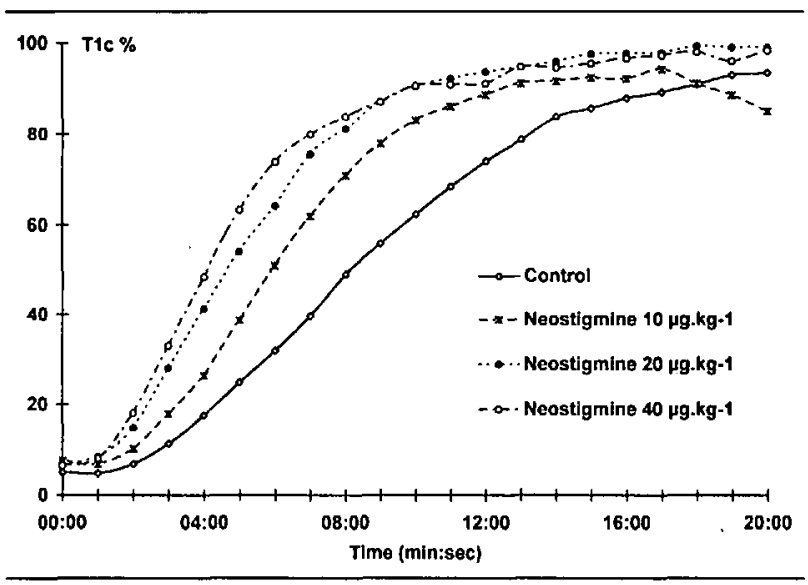

FIGURE 1 Recovery profile of Tlc for the four study groups during the 20 min after administration of the study medication. Time to $\mathrm{Tl}$ lc $>95 \%$ was decreased for the three neostigmine groups compared with placebo $(P<0.01)$.

compared with placebo and the $10 \mu \mathrm{g} \cdot \mathrm{kg}^{-1}$ neostigmine groups, but no difference was found among these last two groups (Table II, Figure 2). Compared with control, the time to recovery of TOF ratio $>0.70$ was reduced by $5.6 \mathrm{~min}$ in both the 20 and the $40 \mu \mathrm{g} \cdot \mathrm{kg}^{-1}$ neostigmine groups.

A slight but significant decrease in heart rate was observed at 10 and $15 \mathrm{~min}$ in all groups but without any difference among them (Figure 3). Similarly, a decrease in systolic blood pressure was observed over the $10 \mathrm{~min}$ period after administration of the reversal

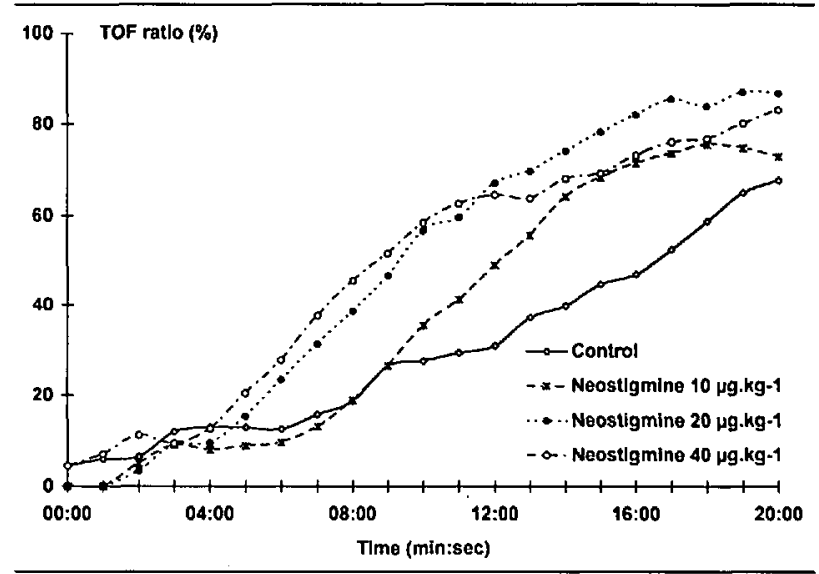

FIGURE 2 Recovery profile of TOF ratio for the four study groups during the $20 \mathrm{~min}$ after administration of study medication. Time to TOF ratio $>70 \%$ was decreased for the 20 and $40 \mu \mathrm{g} \cdot \mathrm{kg}^{-1}$ neostigmine groups compared with the $10 \mu \mathrm{g} \cdot \mathrm{kg}^{-1}$ neostigmine group $(P<0.05)$ and with the control group $(P<0.001)$.

agent but there were no differences among four groups (Figure 3) (Table II). Postoperative nausea and vomiting occurred infrequently in the recovery room, with no differences among the four groups $(2,3,1$ and 1 patients in the control, and the 10,20 , and $40 \mu \mathrm{g} \cdot \mathrm{kg}^{-1}$ neostigmine groups respectively).

\section{Discussion}

The main findings of this study were first, the effectiveness of neostigmine compared with placebo as an antagonist of mivacurium-induced neuromuscular blockade, 


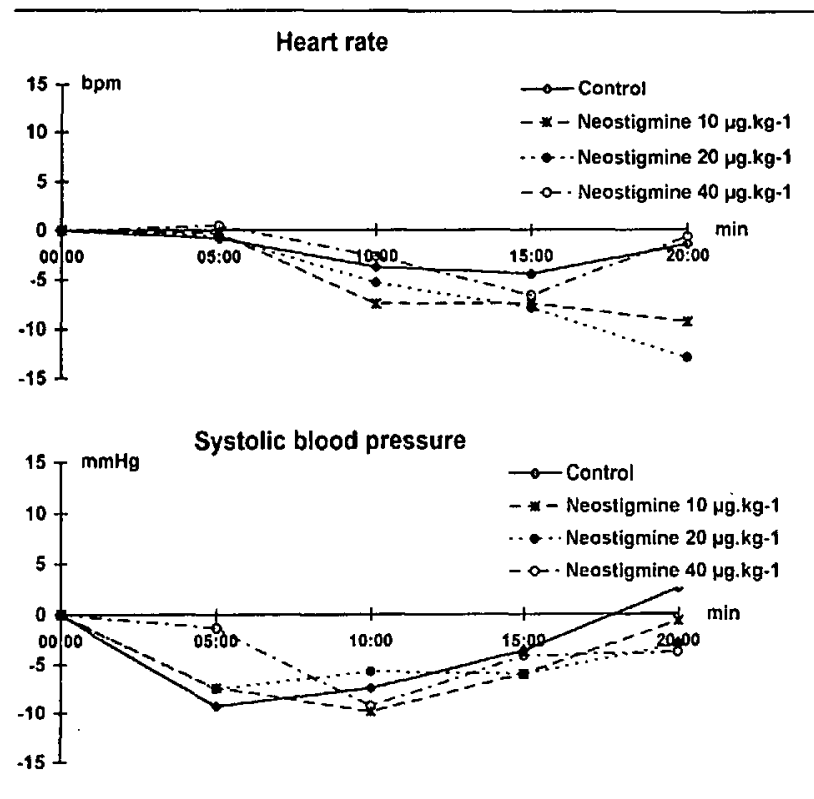

FIGURE 3 Heart rate and systolic blood pressure changes during the $20 \mathrm{~min}$ after administration of study medication. No differences were observed at any time among the four study groups.

and second, that the optimal dose of neostigmine seems to be $20 \mu \mathrm{g} \cdot \mathrm{kg}^{-1}$. Although $10 \mu \mathrm{g} \cdot \mathrm{kg}^{-1}$ reduced the time to recovery of $\mathrm{Tlc}>95 \%$, it was not different from placebo in time to TOF ratio $>70 \%$, which is considered an index of adequacy of recovery of neuromuscular function. A ceiling effect appeared with neostigmine at a dose of $20 \mu \mathrm{g} \cdot \mathrm{kg}^{-1}$, with no further improvement in any of the recovery parameters after $40 \mu \mathrm{g} \cdot \mathrm{kg}^{-1}$. With these last two doses, the mean recovery time of TOF ratio $>0.70$ was reduced by $5.6 \mathrm{~min}$ compared with spontaneous recovery. Since we did not perform a power analysis, we cannot exclude the presence of a difference between the 20 and $40 \mu \mathrm{g} \cdot \mathrm{kg}^{-1}$ groups (type II statistical error). However, even if such a difference does exist, it would probably not be clinically relevant.

These results are in agreement with those of Naguib et al. who found that neostigmine accelerates recovery from mivacurium neuromuscular blockade compared with spontaneous recovery. ${ }^{15}$ However, in that study the observation period was limited to the first $10 \mathrm{~min}$ after administration of neostigmine, allowing only the determination of the dose of neostigmine to achieve $50 \%$ and $70 \%$ recovery of the first twitch after $10 \mathrm{~min}$, (2.0 and $4.7 \mu \mathrm{g} \cdot \mathrm{kg}^{-1}$ respectively). The dose response curve of neostigmine on complete recovery was not studied. Also, incremental bolus doses of mivacurium were used instead of an infusion, thus Naguib's data would not necessarily be relevant to the clinical situation of reversal of neuromuscular blockade at the end of an infusion, although no accumulation has been demonstrated even after a prolonged infusion of mivacurium. ${ }^{4}$ More recently Bevan et al. also reported that neostigmine accelerated recovery from an infusion of mivacurium. ${ }^{14}$ Their conclusion that there seems to be no benefit to the use of doses larger than $20 \mu \mathrm{g} \cdot \mathrm{kg}^{-1}$ is in accordance with the present study. However, the study of Bevan $e t a l$. was mainly designed to compare edrophonium and neostigmine reversal of mivacurium between adults and children. There also, the measurement period was limited to the first $10 \mathrm{~min}$ following administration of the reversal drug and neostigmine was associated with a greater recovery than placebo after 10 $\mathrm{min}$, but no indication of the time to adequate recovery with or without neostigmine was reported. Savarese et al. observed that neostigmine hastened $\mathrm{Tl}$ recovery by four minutes compared with spontaneous recovery. ${ }^{3}$ However, their study was not primarily designed to investigate the antagonism of neostigmine, and their data were drawn from only six patients who all received $60 \mu \mathrm{g} \cdot \mathrm{kg}^{-1}$ neostigmine.

Anticholinesterase agents such as neostigmine are believed to antagonize the effect of non depolarizing muscle relaxants by inhibiting acetylcholinesterase, thereby increasing the concentration of acetylcholine at the neuromuscular junction and competitively counteracting the effect of muscle relaxants. ${ }^{6}$ However, neostigmine also inhibits plasma cholinesterases. ${ }^{16}$ Since plasma cholinesterases are responsible for the hydrolysis of mivacurium, their antagonism with agents such as neostigmine might delay the metabolism and elimination of mivacurium. Therefore, it is not surprising that the efficacy of neostigmine as an antagonist of mivacurium has been questioned. ${ }^{3-5}$ Kao et al. reported that $70 \mu \mathrm{g} \cdot \mathrm{kg}^{-1}$ neostigmine almost doubled the time to recovery of TOF ratio to $90 \%$ compared with spontaneous recovery. 12 Szenohradszky et al. reported that neostigmine inhibition of plasma cholinesterase probably impairs hydrolysis of mivacurium. ${ }^{13}$ Cook et al. also reported that neostigmine inhibits the in vitro metabolism of mivacurium in a dosedependent fashion, although neostigmine still accelerated the recovery from mivacurium-induced neuromuscular blockade. ${ }^{17}$ The study of Yang et al. suggested that different plasma concentrations of neostigmine have different inhibitory effects on acetylcholinesterases and on plasma cholinesterases. ${ }^{18}$ Their data may explain the conflicting observations that neostigmine increases the speed of recovery of mivacurium while at the same time impairing its hydrolysis. In low concentration neostigmine inhibits acetylcholinesterase, increasing the concentration of acetylcholine at the neuromuscular junction. However, this same concentration of neostigmine might only partially inhibit plasma cholinesterases responsible for the 
hydrolysis of mivacurium since a higher concentration of neostigmine appears to be necessary for complete inhibition of plasma cholinesterases. ${ }^{18}$ This might also explain that, in the present study, $20 \mu \mathrm{g} \cdot \mathrm{kg}^{-1}$ neostigmine was as effective as $40 \mu \mathrm{g} \cdot \mathrm{kg}^{-1}$ for reversal of mivacurium.

Because of the rapid spontaneous rate of recovery of mivacurium, it has been suggested that its antagonism, even after an infusion, would rarely be indicated. ${ }^{3-5}$ It could be argued that, with careful appraisal of the end of surgery, reversal could be avoided in most circumstances. The present study was not designed to determine whether antagonism of mivacurium with neostigmine was necessary in the clinical setting. However Bevan et al. reported recently that 6 of 25 (24\%) adult patients who did not received edrophonium at the end of a mivacurium infusion arrived in the recovery room with residual neuromuscular block. ${ }^{19}$ Thus, reversal with anticholinesterases is probably frequently necessary even with a short acting muscle relaxant such as mivacurium. Current dosage recommendations for reversal of intermediate duration muscle relaxants with neostigmine range from 40 to 70 $\mu \mathrm{g} \cdot \mathrm{kg}^{-1} .{ }^{6}$ The present study suggests that smaller doses are probably more appropriate for short acting drugs such as mivacurium. Miller $e t$ al. reached similar conclusions about reversal doses of edrophonium. ${ }^{20}$ In addition to the economic considerations, a lower incidence of cardiovascular, respiratory and gastrointestinal side effects of anticholinesterase agents might be expected. However, in this study, no cardiovascular (heart rate, blood pressure) side effects associated with the use of neostigmine were observed. The decreases in heart rate and systolic blood pressure were not different among the four groups and was probably related to the end of surgical stimulation while the anaesthesia level was kept unchanged during the reversal period. Likewise, postoperative nausea and vomiting was a rare event in all four groups. This last observation most probably can be explained by the use of propofol in the anaesthetic technique and by the short postoperative observation period $(60 \mathrm{~min})$. Finally, these results should be interpreted cautiously since this study was not designed primarily to measure the cardiovascular effects of reversal and PONV events, which were only secondary endpoints.

The objectives of this study were to assess the efficacy of neostigmine for reversal of mivacurium, and to determine its optimal dose. We considered that a treatmenteffect analysis would be more appropriate than an intention-to-treat analysis. Six patients who were included in the study were subsequently excluded from the final analysis. Of these, three had an excessive recovery of $\mathrm{Tl}$ at the end of infusion (NS group: 1 patient, $\mathrm{Tl}=23 \%$; neostigmine $20 \mu \mathrm{g} \cdot \mathrm{kg}^{-1}$ group: one patient, $\mathrm{Tl}=31 \%$; neostigmine $40 \mu \mathrm{g} \cdot \mathrm{kg}^{-1}$ group: one patient, $\mathrm{Tl}=17 \%$ ) and were excluded since the aim was to study reversal of profound block $(>90 \%)$. One patient who had no spontaneous recovery until $45 \mathrm{~min}$ after the initial bolus of mivacurium was withdrawn from the study. On the other hand, a patient in the $10 \mu \mathrm{g} \cdot \mathrm{kg}^{-1}$ neostigmine group who needed rescue reversal medication because of incomplete recovery $(\mathrm{Tlc}=49 \%$, TOF ratio $=11 \%) 20 \mathrm{~min}$ after the injection of the study medication was retained for the analysis. Unfortunately, measurement of plasma cholinesterase activity was not performed in this study and these last two patients could not subsequently be reached for plasma cholinesterase activity measurement.

In conclusion, this study demonstrated the efficacy of neostigmine in accelerating the recovery of neuromuscular block at the end of an infusion of mivacurium. A dose of neostigmine $20 \mu \mathrm{g} \cdot \mathrm{kg}^{-1}$ appears to be optimal with no further reduction in recovery time obtained from a larger dose.

\section{Acknowledgments}

The authors thank the research assistants Mrs. C. Plante and Mr. P.A. Gagné and A. Tremblay, and Mrs. Line Godin for her help with preparation of the manuscript.

\section{References}

1 Cook DR, Stiller RL, Weakly JN, Chakravorti S, Brandom $B W$, Welch $R M$. In vitro metabolism of mivacurium chloride (BW B1090U) and succinylcholine. Anesth Analg 1989; 68: 452-6.

2 Lien CA, Schmith VD, Embree PB, Belmont MR, Wargin $W A$, Savarese $J$. The pharmacokinetics and pharmacodynamics of the stereoisomers of mivacurium in patients receiving nitrous oxide/opioid/barbiturate anesthesia. Anesthesiology 1994; 80: 1296-302.

3 Savarese J], Ali HH, Basta SJ, et al. The clinical neuromuscular pharmacology of mivacurium chloride (BW B1090U). A short-acting nondepolarizing ester neuromuscular blocking drug. Anesthesiology 1988; 68: 723-32.

4 Diefenbach $C$, Mellinghoff $H$, Lynch $J$, Buzello $W$. Mivacurium: dose-response relationship and administration by repeated injection or infusion. Anesth Analg 1992; 74: 420-3.

5 Brull SJ, Connelly NR, Silverman DG. Recovery of train-of-four after mivacurium. Can J Anaesth 1995; 42: 28-31.

6 Bevan DR, Donati F, Kopman AF. Reversal of neuromuscular blockade. Anesthesiology 1992; 77: 785-805.

7 Miller RD, Van Nybuis LS, Eger EI II, Vitez TS, Way WL. Comparative times to peak effect and durations of action of neostigmine and pyridostigmine. Anesthesiology 1974; 41: 27-33. 
8 Ding $\Upsilon$, Fredman $B$, White $P F$. Use of mivacurium during laparoscopic surgery: effect of reversal drugs on postoperative recovery. Anesth Analg 1994; 78: 450-4.

9 Ostheimer GW. A comparison of glycopyrrolate and atropine during reversal of nondepolarizing neuromuscular block with neostigmine. Anesth Analg 1977; 56: 182-6.

10 King MJ, Milazkiewicz R, Carli F, Deacock AR. Influence of neostigmine on postoperative vomiting. Br J Anaesth 1988; 61: 403-6.

11 Watcha MF, Safavi FZ, McCulloch DA, Tan TSH, White PF. Effect of antagonism of mivacurium-induced neuromuscular block on postoperative emesis in children. Anesth Analg 1995; 80: 713-7.

12 Kao YJ, Le ND. The reversal of profound mivacuriuminduced neuromuscular blockade. Can J Anaesth 1996; 43: 1128-33.

13 Szenohradszky J, Lau $M$, Brown $R$, Sharma $M L$, Fisher $D M$. The effect of neostigmine on twitch tension and muscle relaxant concentration during infusion of mivacurium or vecuronium. Anesthesiology 1995; 83: 83-7.

14 Bevan JC, Tousignant C, Stephenson C, et al. Dose responses for neostigmine and edrophonium as antagonists of mivacurium in adults and children. Anesthesiology 1996; 84: 354-61.

15 Naguib M, Abdulatif M, Al-Gbamdi A, Hamo I, Noubeid $R$. Dose-response relationships for edrophonium and neostigmine antagonism of mivacurium-induced neuromuscular block. Br J Anaesth 1993; 71: 709-14.

16 Mirakbur RK, Lavery TD, Briggs LP, Clarke RSJ. Effects of neostigmine and pyridostigmine on serum cholinesterase activity. Can Anaesth Soc J 1982; 29: 55-8.

17 Cook DR, Chakravorti S, Brandom BW, Stiller RL. Effects of neostigmine, edrophonium and succinylcholine on the in vitro metabolism of mivacurium : clinical correlates. Anesthesiology 1992; 77: A948.

18 Yang HS, Goudsouzian N, Martyn JAJ. Pseudocholinesterase-mediated hydrolysis is superior to neostigmine for reversal of mivacurium-induced paralysis in pitro. Anesthesiology 1996; 84: 936-44.

19 Bevan DR, Kabvaji R, Ansermino JM, et al. Residual block after mivacurium with or without edrophonium reversal in adults and children. Anesthesiology 1996; 84: 362-7.

20 Miller DR, Bryson G, Martineau RJ, et al. Edrophonium requirements for reversal of deep neuromuscular block following infusion of mivacurium. Can J Anaesth 1995; 42: 996-1002. 